\title{
Growth of TiC/a-C:H nanocomposite films by reactive high power impulse magnetron sputtering under industrial conditions
}

\author{
Mattias Samuelsson, Kostas Sarakinos, Hans Högberg, Erik Lewin, Ulf Jansson, \\ Bengt Wälivaara, Henrik Ljungcrantz and Ulf Helmersson
}

\section{Linköping University Post Print}

N.B.: When citing this work, cite the original article.

Original Publication:

Mattias Samuelsson, Kostas Sarakinos, Hans Högberg, Erik Lewin, Ulf Jansson, Bengt Wälivaara, Henrik Ljungcrantz and Ulf Helmersson, Growth of TiC/a-C:H nanocomposite films by reactive high power impulse magnetron sputtering under industrial conditions, 2012, Surface \&amp; Coatings Technology, (206), 8-9, 2396-2402.

http://dx.doi.org/10.1016/j.surfcoat.2011.10.039

Copyright: Elsevier

http://www.elsevier.com/

Postprint available at: Linköping University Electronic Press http://urn.kb.se/resolve?urn=urn:nbn:se:liu:diva-67485 


\title{
Growth of Ti-C nanocomposite films by reactive high power impulse magnetron sputtering under industrial conditions
}

\author{
Mattias Samuelsson ${ }^{1,2, *}$, Kostas Sarakinos ${ }^{1}$, Hans Högberg ${ }^{1,2}$, Erik Lewin ${ }^{3,4}$, Ulf \\ Jansson $^{3}$, Bengt Wälivaara ${ }^{2}$, Henrik Ljungcrantz ${ }^{2}$, and Ulf Helmersson ${ }^{1}$ \\ ${ }^{1}$ Department of Physics, Chemistry, and Biology, IFM, Linköping University, SE-581 83 \\ Linköping, Sweden \\ ${ }^{2}$ Impact Coatings AB, Westmansgatan 29, SE-582 16 Linköping, Sweden \\ ${ }^{3}$ Department of Materials Chemistry, The Angström Laboratory, Uppsala University, P.O. \\ Box 538, SE-751 21 Uppsala, Sweden \\ ${ }^{4}$ Laboratory of Nanoscale Materials Science Empa - Swiss Federal Laboratories for \\ Materials Science and Technology, Überlandstrasse 129, CH-8600 Dübendorf, Switzerland \\ * Corresponding author. E-mail: matsa757@ifm.liu.se \\ Complete Address: Mattias Samuelsson \\ Department of Physics, Chemistry \& Biology, \\ Linköping University, \\ SE-581 83, Linköping, \\ Sweden. \\ Office Phone: \\ 0046-13-282712 \\ Fax: \\ 0046-13-137568
}

\begin{abstract}
Titanium carbide (TiC) films were deposited employing high power impulse magnetron sputtering (HiPIMS) and direct current magnetron sputtering (DCMS) in an $\mathrm{Ar}-\mathrm{C}_{2} \mathrm{H}_{2}$ atmosphere of various compositions. Analysis of the structural, bonding and compositional characteristics revealed that the deposited films are either TiC and hydrogenated amorphous carbon (a-C:H) nanocomposites, nanocrystalline $\mathrm{TiC}$, or $\mathrm{Ti} / \mathrm{TiC}$, depending on the $\mathrm{C} / \mathrm{Ti}$ ratio. It was found that Ti-C films grown by HiPIMS show a C/Ti ratio of close to 1 for a wide $\mathrm{C}_{2} \mathrm{H}_{2}$ flow range (4-15 sccm), with free $\mathrm{C}$ ranging from 0 to $20 \%$. Thus, films ranging from near stoichiometric single phase $\mathrm{TiC}$ to $\mathrm{TiC} / \mathrm{a}-\mathrm{C}: \mathrm{H}$ nanocomposites can be synthesized. This was not the case for DCMS, where films grown using similar deposition rates as for HiPIMS
\end{abstract}


formed larger fractions of amorphous $\mathrm{C}$ matrix, thus being nanocomposites in the same $\mathrm{C}_{2} \mathrm{H}_{2}$ (above $4 \mathrm{sccm}$ ) flow range. For a $\mathrm{C} / \mathrm{Ti}$ ratio of 1 the resistivity is low $\left(4-8 \times 10^{2} \mu \Omega \mathrm{cm}\right)$ for the HiPIMS films, and high $\left(>100 \times 10^{2} \mu \Omega \mathrm{cm}\right)$ for the DCMS films. The hardness also shows a big difference with 20-27 and 6-10 GPa for HiPIMS and DCMS grown films, respectively.

Keywords: HiPIMS, HPPMS; Reactive magnetron sputtering; TiC, a-C:H, Nanocomposite 


\section{Introduction}

$\mathrm{TiC}$ is a binary compound ( $\mathrm{NaCl}$ crystal structure) that exhibits desirable physical properties, such as high hardness, high melting point, chemical inertness, and high electrical conductivity [1]. In thin film form $\mathrm{TiC}$ is deposited employing chemical vapor deposition [2], as well as a variety of plasma assisted physical vapor deposition (PVD) techniques. The latter include cathodic arc evaporation $[3,4,5]$ and magnetron sputtering, either in non-reactive mode, using a single compound Ti-C target material [6], two elemental targets $[7,8,9,10,11]$, or reactively from a metallic Ti target using a hydrocarbon gas $\left(\mathrm{CH}_{4}, \mathrm{C}_{2} \mathrm{H}_{2}\right)$ as source of $\mathrm{C}[6,7,12]$. Another feature of the Ti-C binary system is the incorporation of free $\mathrm{C}$ at the $\mathrm{TiC}$ grain boundaries forming a tissue phase [13]. While thermodynamics predict this to occur above the C solubility limit ( 49 at. \% C) [1,14], in physical vapor deposited thin films free C may appear already for as low C contents as $\sim 20$ at. \% [15]. This $\mathrm{C}$ content is below the vacancy limit for phase pure $\mathrm{TiC}(\sim 35$ at. \% C), below which Ti/TiC is anticipated. Formation of free $\mathrm{C}$ is accompanied by the formation of a nanocomposite microstructure in which nanosized metal carbide grains are embedded in an amorphous $\mathrm{C}$ [13] or hydrogenated amorphous $\mathrm{C}$ [16,17] (when hydrocarbons are used as reactive gases) matrix, denoted as TiC/a-C and TiC/a-C:H, respectively. The nanocomposite thin films can exhibit high electrical conductivity, high hardness, ductility as well as low friction and wear rate which enable their utilization as e.g. self lubricating, low friction coatings [18,19] and electrical contacts [20]. The mechanical strength, the electrical and tribological properties of the nanocomposite films are determined by the $\mathrm{C} / \mathrm{Ti}$ ratio, the relative fraction of the a-C(:H) matrix, and the size of the TiC grains [7,18,19,21,22,23].

It is known that the microstructural characteristics of films grown by PVD techniques are controlled by a variety of process parameters, e.g. the growth temperature, the composition of the gas atmosphere, and the energy transferred from the energetic plasma particles to the film 
forming species [24]. High power impulse magnetron sputtering (HiPIMS) is a technique which provides large fluxes of energetic ions to the growing film. This is achieved by applying short (typically several 10's of $\mu \mathrm{s}$ ) high power density unipolar pulses with a duty cycle of a few $\%$ to the sputtering target [25,26,27]. This mode of operation leads to the generation of dense plasmas with electron densities up to $\sim 10^{19} \mathrm{~m}^{-3}$ [28], several orders of magnitude higher than those in conventional magnetron sputtering techniques, e.g. direct current magnetron sputtering (DCMS) [29,30]. This, in turn, causes ionization of a large fraction of the gas and sputtered atoms [29,31,32] allowing for an intense energetic bombardment of the growing film. This has been shown to lead to the growth of smooth and dense elemental [33] and reactively deposited compound films [34,35,36], and enable control over their phase composition [37,38,39], microstructure [37,40,41], as well as mechanical [40] and optical $[38,39]$ properties. Furthermore, when employing HiPIMS in a reactive mode for oxide deposition an increased process stability in the transition regime between the metallic and the compound mode has been reported $[42,43,44]$, allowing for a better control of the incorporation of the reactive gas species and thus of the atomic composition of the growing film. Moreover, the increased plasma density in a HiPIMS discharge can influence the plasma chemistry [45]. This may be relevant, since the plasma itself is a carbon source in reactive $\mathrm{C}_{2} \mathrm{H}_{2}$ processes [46,47].

It is therefore evident that in comparison to conventional magnetron sputtering processes, the HiPIMS process exhibits enhanced capabilities for controlling plasma conditions and the microstructure, composition, and the properties of reactively sputtered compound films. This potential for metal carbide nanocomposite films in general, and $\mathrm{TiC} / \mathrm{a}-\mathrm{C}(\mathrm{H})$ in particular, remains to be demonstrated.

The present study explores the feasibility of reactive HiPIMS for the growth of TiC/a-C:H thin films, a previously well studied material system of technological relevance to 
applications, and its implications for the film properties. Ti-C thin films are deposited employing HiPIMS, as well as DCMS for reference, in a reactive $A r-\mathrm{C}_{2} \mathrm{H}_{2}$ atmosphere of various compositions. The chemical bonding, atomic composition, and the microstructure of the films at the various deposition conditions are investigated and correlated with their mechanical and electrical properties.

\section{Experimental procedures}

Depositions were carried out in a commercial Inline Coater 400 (Impact Coatings) type high vacuum system with a base pressure below $6.7 \times 10^{-4} \mathrm{~Pa}\left(5 \times 10^{-3} \mathrm{mTorr}\right)$. The working principle of the deposition system includes sequential, individual processes in isolated, $0.28 \mathrm{~m}$ high and $0.4 \mathrm{~m}$ in diameter, cylindrical chambers, and is described in detail elsewhere [48]. The experiments were performed employing a rectangular $(21 \mathrm{~cm} \times 10 \mathrm{~cm})$ Ti target (purity > 99.3\%). The target was mounted on a magnetron cathode which exhibited a magnetic field strength of 350 Gauss at the race track. Films were deposited on $\mathrm{Si}(100)$ and $\sim 100 \mathrm{~nm} \mathrm{SiO}_{2} /$ Si substrates, which prior to deposition were supersonically cleaned in isopropanol at $70{ }^{\circ} \mathrm{C}$ for at least 15 minutes. No substrate rotation or intentional substrate heating was used during the depositions, while a bias potential of $-150 \mathrm{~V}$ was applied on the substrate. Each deposition was preceded by three minutes Ar plasma etching at pressure of $1 \mathrm{~Pa}$ (7.5 mTorr) by applying unipolar voltage pulses with an amplitude of $450 \mathrm{~V}$, a pulse width of $1.6 \mu \mathrm{s}$, and at a frequency of $250 \mathrm{kHz}$ to remove surface contaminants from the substrates. Films were grown for 15 minutes at a constant $\operatorname{Ar}$ (purity 99.9999\%) flow of $30 \mathrm{sccm}$, resulting in a partial pressure of $1 \mathrm{~Pa}$ (7.5 mTorr) while the $\mathrm{C}_{2} \mathrm{H}_{2}$ (minimum purity 99.6\%) flow was varied from 0 to $20 \mathrm{sccm}$, resulting in slight increases in the total pressure up to $1.1 \mathrm{~Pa}$. The target-tosubstrate distance was $12 \mathrm{~cm}$. Power was supplied to the sputtering target by a Sinex 3 (Chemfilt Ionsputtering) generator, capable of operating either in voltage regulated HiPIMS mode, or power regulated DCMS mode. Depositions were performed both in DCMS and 
HiPIMS modes. The DCMS processes were operated at constant power of $0.6 \mathrm{~kW}$. For the HiPIMS depositions, an average target power of $2 \mathrm{~kW}$ was maintained by adjusting the target voltage. The pulse repetition frequency was $400 \mathrm{~Hz}$ and the pulse width was approximately 75 $\mu \mathrm{s}$. The larger average target power used in HiPIMS experiments (as compared to the DCMS ones) was selected in order to obtain equal deposition rates from a metallic target for both techniques. Thus, for similar arrival rates of film forming species, the ion-to-neutral ratio and ion energy, which are different for DCMS and HiPIMS, were the main parameters varied. This experimental strategy was adopted to facilitate a straightforward comparison of the deposition processes and shed light on the fundamental film growth mechanisms. Moreover, a few control experiment films were grown employing DCMS at an average power equal to that used for the HiPIMS depositions. This was done to allow direct comparison of the two deposition methods, as well as to decouple possible effects of the choice of deposition method (i.e. DCMS and HiPIMS) and the average target power applied to the cathode. The deposition sequence of the samples was randomized. Prior to each deposition the target was sputter cleaned in constant current mode for at least 10 minutes.

The crystal structure of the deposited films was investigated by means of X-ray diffractometry (XRD), performed in a diffractometer equipped with a $\mathrm{Cu} \mathrm{K} \alpha$ source operating in both $\theta-2 \theta$ and grazing incidence geometries. Film thicknesses, as well as surface and cross-sectional morphology were obtained from scanning electron microscopy (SEM, LEO 1550 Gemini) operating at $10 \mathrm{keV}$. The film thickness was measured on fractured specimen cross sections, and averaged for at least five measurements collected from sites spanning the full substrate width. Compositional and chemical analysis was performed by X-ray photoelectron spectroscopy (XPS) using a Physical Electronics Quantum 2000 spectrometer equipped with a monochromatic Al Ka X-ray source. The XPS sensitivity factors were calibrated against a reference sample with a known composition as previously determined by time-of-flight elastic 
recoil detection analysis (ToF-ERDA) [49]. Owing to the fact that the samples were analyzed during different sessions, and that the XPS equipment may be subject to charge referencing, the binding energies recorded may appear shifted when comparing different analysis sessions. To circumvent this issue, already analyzed samples were re-measured in each session, and comparison allowed accurate deduction of any shifts in binding energy between sessions. The XPS data presented in figures have been shifted according to this procedure. Composition was determined from sputter depth profiles attained using $4 \mathrm{keV} \mathrm{Ar}^{+}$ions rastered over a $2 \times 2 \mathrm{~mm}$ area. High resolution spectra were recorded at an approximate depth of $15 \mathrm{~nm}$ after sputtering using $200 \mathrm{eV} \mathrm{Ar}^{+}$rastered over a $1 \times 1 \mathrm{~mm}$ area. In the latter case, low ion energy was used in order to minimize the contribution of sputter damage, in the high resolution spectra; previous studies has shown that no preferential sputtering (i.e. no stoichiometry changes) occurs in this system using $4 \mathrm{keV} \mathrm{Ar}^{+}$[50]. The peaks in the recorded spectra were fitted for Shirley background and $20 \%$ Lorentzian peak functions. The fitting enabled to calculate the area below each peak. The instrumental error in the XPS measurements and peak fits were both estimated to be $5 \%$ or less. To evaluate the amount of $\mathrm{H}$ incorporation in the films, selected samples were analyzed using ToF-ERDA using $40 \mathrm{MeV}^{127} \mathrm{I}^{9+}$ ions. The ion incidence angle relative to the surface normal was $67.5^{\circ}$ and the detector was positioned at a recoil scattering angle of $45^{\circ}$. For evaluation of the ToF-ERDA data the CONTES code was employed [51], and a reference sample with known $\mathrm{H}$ content was used for calibration of the data. Electrical properties were evaluated by four point probe measurements on samples grown on the insulating $\mathrm{SiO}_{2} / \mathrm{Si}$ substrates, using a Model 280C (Four Dimension) apparatus. The measured sheet resistivity values were multiplied by the respective film thicknesses as assessed by cross sectional SEM measurements to obtain the resistivity. Films grown on the $\mathrm{SiO}_{2}$ substrates showed no differences to the films grown on $\mathrm{Si}$, as confirmed by XRD and cross section SEM. Nano indentation (Umis 2000) was employed to measure the hardness values. A 
Berkovich tip was indented a minimum of 10 times at a load of $5 \mathrm{mN}$, corresponding to indentation depths of $\sim 10-15 \%$ of the film thickness, yielding a relative hardness deviation of no more than $\sim 6 \%$. The load was chosen after investigating several indentation loads, thus finding a value causing plastic deformation, while showing marginal influence of surface roughness, and minimizing any influence of the substrate. The hardness was evaluated according to the Oliver-Pharr method [52].

\section{Results and discussion}

Figure 1 (a) presents the effect of the $\mathrm{C}_{2} \mathrm{H}_{2}$ flow on the C/Ti ratio of the DCMS and HiPIMS films deposited at matched deposition rates, i.e. using average powers of $0.6 \mathrm{~kW}$ and $2 \mathrm{~kW}$, respectively. The C/Ti increase is similar up to a $\mathrm{C}_{2} \mathrm{H}_{2}$ flow of $6 \mathrm{sccm}$ for both DCMS and HiPIMS. At flows larger than $6 \mathrm{sccm}$ the DCMS process results in a steep increase in $\mathrm{C}$ content in the films, while the $\mathrm{C} / \mathrm{Ti}$ ratio in HiPIMS grown films saturates towards unity, and remains stable until the $\mathrm{C}_{2} \mathrm{H}_{2}$ flow surpasses $15 \mathrm{sccm}$. It is well established [53] that in reactive sputtering processes the film composition largely depend on the coverage of the target surface by the corresponding compound. Upon increasing the reactive gas flow the target surface transforms from being metallic to compound, resulting in an increase of the reactive gas species incorporation in the film and a decrease of the deposition rate. In the transition zone between the metallic and the compound sputtering modes small alterations of the reactive gas flow typically result in abrupt changes in the target coverage and thereby in the deposition rate as well as in the film composition, as seen for DCMS in Figure 1 (a) and (b). Moreover, in many cases the transition zone is unstable, i.e. within the transition zone rapid drift in the process parameters (deposition rate, target voltage and reactive gas partial pressure) is observed [53] accompanied by a hysteresis. However, the data presented in Figure 1 show instabilities in film composition and deposition rates only for the DCMS grown films. The composition of the HiPIMS grown films instead stabilize at stoichiometric composition 
and much higher reactive gas flows is needed to alter the composition further. These findings can in part be understood in view of the results obtained by Wallin and Helmersson [42], Sarakinos et al. [43], and Aiempanakit et al. [44] who have reported that HiPIMS allows for less abrupt process behavior in the transition zone as compared to DCMS. This has been attributed to the intense target etching [42] and the rarefaction of the reactive gas [54] during the pulse on-time, in combination with low plasma activity in-between the pulses $[42,55]$ which prevent build-up of compound material on the target surface. Further possible explanation for the $\mathrm{C} / \mathrm{Ti}$ ratio not exceeding stoichiometry is removal of excess free $\mathrm{C}$ by chemical sputtering at the growing surface [56]. This phenomenon is readily observed for example during chemical vapor deposition growth of diamond like carbon [57]. For efficient chemical etching to occur, the presence of $\mathrm{H}$ in combination with ion bombardment is required [58,59]. As mentioned above, it is established that the HiPIMS process offer a high degree of ion bombardment to the growing film [25]. Moreover, the number of plasma chemical reactions of $\mathrm{C}_{2} \mathrm{H}_{2}$ depends on the plasma density; higher plasma density yields more reactions [45], often with $\mathrm{H}$ as by-product [60,61], and increased amounts of $\mathrm{H}$ available for chemical sputtering. Thus, chemical sputtering should be more pronounced during the HiPIMS than the DCMS process.

Furthermore, for the present material system (TiC), it has been shown that upon ion irradiation $\mathrm{C}$ is preferentially sputtered (here physical sputtering, as oppose to chemical sputtering discussed above) from the TiC due to differences in sputtering yield between $\mathrm{C}$ and Ti when in compound form $[46,62,63]$. While this effect should be seen for both deposition methods studied here, the average ion current towards the substrate is reported to be typically twice as high in HiPIMS as in DCMS processes for the same average power, and two orders of magnitude higher during the pulse on-time [25]. Consequently, the films grown under 
HiPIMS conditions are likely to be subjected to an increased preferential sputtering of $\mathrm{C}$ which could limit the $\mathrm{C}$ content.

High resolution XPS spectra for the C1s region for the films grown by DCMS at $0.6 \mathrm{~kW}$ target average power, and HiPIMS are plotted in Fig. 2 (a) and (b), respectively. The C/Ti ratio corresponding to the data presented in Figure 1 (a) is provided for each curve. In the spectra three peaks at binding energies $\sim 282 \mathrm{eV}, \sim 283 \mathrm{eV}$ and $\sim 284.5 \mathrm{eV}$ are observed. The peak at $\sim 282 \mathrm{eV}$ corresponds to the $\mathrm{C}$ - $\mathrm{Ti}$ bonds and is more pronounced throughout the film series grown by HiPIMS until the stoichiometry limit is surpassed. On the other hand, the spectra recorded for DCMS grown films exhibit a comparably more prominent peak at $\sim 284.5$ $\mathrm{eV}$ corresponding to $\mathrm{C}-\mathrm{C}$ bonds. The intermediate peak located at $\sim 283 \mathrm{eV}$ is denoted as $\mathrm{C}$ $\mathrm{Ti}^{*}$ and is a component in the XPS spectra known to be present in the nanocomposite TiC/a-C structure [64]. The high resolution XPS spectra of the Ti2p region (not shown) for films grown with the same deposition rate, and with a $\mathrm{C} / \mathrm{Ti}$ ratio of $\sim 0.35$ for both deposition methods, reveal that the films contain Ti-Ti bonds as well as Ti-C. These coatings are thus nanocomposite $\mathrm{Ti} / \mathrm{TiC}$. However, for films exhibiting $\mathrm{C} / \mathrm{Ti}>0.4$ no $\mathrm{Ti}-\mathrm{Ti}$ bonds were observed, for either deposition method.

Figure 3 shows (a) the relative $\mathrm{C}-\mathrm{C}$ bond peak area $\left(\mathrm{A}_{\mathrm{C}-\mathrm{C}}\right)$ with respect to the total area of all peaks $\left(\mathrm{A}_{\text {tot }}\right)$ attained from curve fits of the high resolution spectra (presented in Figure 2), and (b) the oxygen content as a function of $\mathrm{C} / \mathrm{Ti}$ ratio. The $\mathrm{A}_{\mathrm{C}-\mathrm{C}} / \mathrm{A}_{\text {tot }}$ ratio serves as a measure of the amount of free $\mathrm{C}$ in the coatings, and ratios above $\sim 0.15$ can be considered as a proof of an additional phase, i.e. free C. The amount of free carbon for the DCMS films at different $\mathrm{C} / \mathrm{Ti}$ ratios in the present study is in reasonable agreement with what has been previously reported in the literature $[15,20,65,66]$, and a second phase is identified for C/Ti ratios above 0.37. This observation shows that the coatings synthesized using DCMS must have a substoichiometric $\mathrm{TiC}_{\mathrm{x}}$ phase; e.g. the coating with a $\mathrm{C} / \mathrm{Ti}$ ratio of 1.27 is found to have a 
stoichiometry of $\mathrm{TiC}_{0.66}$ (after subtracting the present free carbon). In contrast, films grown using HiPIMS exhibit no free carbon up to $\mathrm{C} / \mathrm{Ti}$ ratios above 1.1 , where a carbide stoichiometry of $\mathrm{TiC}_{0.94}$ could be calculated for the film exhibiting a $\mathrm{C} / \mathrm{Ti}$ ratio of 1.11 (after subtracting the present free carbon). From the samples without any Ti phase (i.e. C/Ti-ratios above 0.4 ) it can thus be concluded that the stoichiometry of the carbide phase is different in coatings from the two processes, with higher carbon content in the TiC phase (i.e. closer to thermodynamic equilibrium) in the HiPIMS case. This can be understood by the notion that the relative amount of free $\mathrm{C}$ and carbide phase in $\mathrm{C}$-based nanocomposites is affected by the energy provided to the film forming species for chemical reactions, i.e. carbide formation, to occur [67]. It is well established that HiPIMS plasmas are characterized by a more intense energetic ion bombardment of the growing film [25], as compared to DCMS, which can explain the comparably lower content of free $\mathrm{C}$ in the HiPIMS grown films. Our findings regarding the free $\mathrm{C}$ in the HiPIMS films are consistent with those of Zehnder and Patscheider [19], who reported similar trends with respect to free $\mathrm{C}$ formation in TiC films by close field unbalanced magnetron sputtering configuration, a setup known to deliver significantly higher ion currents to the substrate than conventional magnetron sputtering setups [68]. Analysis of XPS C1s spectra recorded from films grown by DCMS at an average power of $2 \mathrm{~kW}$ with $\mathrm{C} / \mathrm{Ti}$ ratios of $\sim 0.4$ delivered $\mathrm{A}_{\mathrm{C}-\mathrm{C}} / \mathrm{A}_{\text {tot }}$ (free $\mathrm{C}$ ) values of $\sim 0.2$. This implies that the trends observed in Figure 3 (a) are a consequence of the choice of deposition method rather than the average power applied to the sputtering target, or the deposition rate. For higher C/Ti ratios, the amount of free carbon increases also for HiPIMS grown films, to levels similar to those of the corresponding DCMS films (see also Figure 2). In Figure 3 (b) it can be seen that the $\mathrm{O}$ content in the HiPIMS films is in the order of 2 at. \% while no clear dependence on the C/Ti ratio is observed. In contrast, in the DCMS films grown at an average power of $0.6 \mathrm{~kW}$, the $\mathrm{O}$ content is notably higher and increases with $\mathrm{C}$ content up to about $\mathrm{C} / \mathrm{Ti}=1$, after which it 
decreases steeply. For the DCMS films grown at $2 \mathrm{~kW}$, the oxygen levels were significantly lower ( $\sim 6$ at. $\%)$, and the $\mathrm{O}$ incorporation is thus an effect of the choice of average power for the DCMS process. Furthermore, the Ti2p peaks (not shown) corresponding to the DCMS films deposited at $0.6 \mathrm{~kW}$ average target power exhibit Ti-O contributions. No Ti-O bonds were found for the HiPIMS films grown at the same deposition rate, which suggests that the $\mathrm{O}$ incorporation did not occur during growth, but likely during post-deposition exposure to the atmosphere.

The $\mathrm{H}$ content was determined for films with a $\mathrm{C} / \mathrm{Ti}$ ratio of $\sim 1$. The results revealed that $\mathrm{H}$ is evenly distributed throughout the film thickness for both DCMS and HiPIMS. It was also found that the film grown by DCMS exhibits twice the amount $(\sim 14 \%)$ of $\mathrm{H}$ compared to the HiPIMS films. This can be understood, considering Figure 3, from which it can be seen that the films grown by DCMS contain approximately twice the amount of a-C matrix to host the H.

Figure 4 shows XRD patterns recorded from films deposited at various conditions. A general observation is that all peaks are broad and of low intensity. The shifted peak positions are often observed for Ti-C, and is typically explained in terms of strained crystallites or stoichiometric variations of the TiC grains $[64,69,70,71,72]$. The film grown by DCMS at an average power of $0.6 \mathrm{~kW}$, Figure 4 (a), without presence of $\mathrm{C}_{2} \mathrm{H}_{2}$ (pure Ti) exhibits a (002) texture typical for low temperature $\mathrm{Ti}$ deposition [73]. Addition of $\mathrm{C}_{2} \mathrm{H}_{2}$ leads to the appearance of peaks suggesting a $\mathrm{NaCl}$ crystal structure, with increasingly broader and less intense peaks as the reactive gas flow increases. This is consistent with the notion that $\mathrm{C}$ acts as a grain refiner hindering grain growth [19]. For the DCMS film exhibiting a C/Ti ratio of 0.36, a peak at $36.7^{\circ}$ is visible. Assuming that this is a (111) peak from a cubic structure and calculating the cell parameter for this peak, gives values around $4.24 \AA$, values too small to unambiguously be assigned to $\mathrm{TiC}$ [14]. It has been suggested that this peak is the result of 12 
coexisting $\mathrm{Ti}$ and $\mathrm{TiC}$ structures [74]. In the case of HiPIMS, as seen Figure 4 (b), the diffraction pattern corresponding to pure Ti film shows a peak, possibly corresponding to the Ti (100) reflection. The peak is broad and of low intensity, likely due to re-nucleation as a result of the intense ion bombardment, as has been suggested by Ehiasarian et al. [35] and Alami et al. [41]. Upon increasing the $\mathrm{C}_{2} \mathrm{H}_{2}$ flow and thus $\mathrm{C}$ incorporation to a C/Ti ratio of 0.37 , a broad peak at $\sim 36.5^{\circ}$ is seen. The notable width suggests small grains, and possibly overlapping reflections from nanosized $\mathrm{TiC}$, as well as $\mathrm{Ti}$ grains. Further increase of $\mathrm{C}$ content results in the appearance of $\mathrm{TiC}$ peaks. These peaks become sharper and more intense as the $\mathrm{C} / \mathrm{Ti}$ ratio increases from 0.85 to 1.14 . This implies that in contrast to the DCMS process, for the HiPIMS process the increase of $\mathrm{C}$ content in the films does not hinder, but rather promote the grain growth. The results obtained from the $\theta-2 \theta$ measurements with respect to peak positions and widths were confirmed by XRD measurements performed in grazing incidence geometry (not shown). The findings in Figure 4 along with the presence of free $\mathrm{C}$ (Figure 2), and the $\mathrm{H}$ presence assessed by ToF-ERDA signify that the deposited films can be classified in three groups depending on the reactive gas flow for the different processes: $\mathrm{Ti} / \mathrm{TiC}_{\mathrm{x}}\left(<4 \mathrm{sccm}\right.$ for both methods), nanocrystalline $\mathrm{TiC}_{\mathrm{x}}$ (for ranges where no Ti-Ti or no C-C bonding could positively be identified, i.e. from 4 to $10 \mathrm{sccm}$ for HiPIMS,

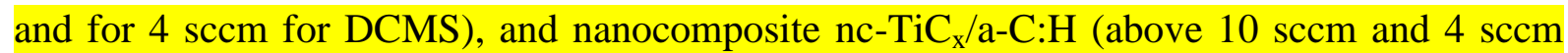
for HiPIMS and DCMS, respectively).

The cross section SEM micrographs presented in Figure 5 demonstrate the influence of the growth conditions at similar deposition rates provided by the two methods employed (i.e. DCMS at $0.6 \mathrm{~kW}$ average power, and HiPIMS) on the microstructure of TiC/a-C:H films of approximately the same $\mathrm{C} / \mathrm{Ti}$ ratios. The DCMS film with $\mathrm{C} / \mathrm{Ti} \approx 0.35$ (Figure 5 (a) exhibits a rough surface and a porous, columnar microstructure, while its HiPIMS counterpart (Figure 5 (b) shows a smoother surface and a more dense structure throughout the film thickness. Such 
morphology differences are often reported when comparing DCMS and HiPIMS; see per example reference 33. The porosity in the DCMS films may facilitate post deposition diffusion of contaminants into the films [75], which in turn can explain the higher O contents of films grown by DCMS (average power $0.6 \mathrm{~kW}$ ) as shown in Figure 3 (b). The DCMS films grown using an average power of $2 \mathrm{~kW}$, see figure 5 (c), contain less oxygen, and show a less porous, although similarly columnar microstructure and rough surface. As the $\mathrm{C}$ content is increased, see Figure 5 (d) and (e), the films grown by DCMS, Figure 5 (e) exhibit less structural features, although still a pronounced columnar microstructure. This observation is in line with earlier studies [76], reporting a transition from columnar to featureless microstructure in TiC/a-C:H nanocomposites with increased C content. Such a microstructure would allow less post deposition diffusion of $\mathrm{O}$ into the structure, and could explain the decrease in the $\mathrm{O}$ content observed for the DCMS grown films of higher C/Ti ratio (see Figure 3 (b).

Previous studies have shown that the carbide grain sizes, the amount of matrix phase, and the microstructure have implications for the hardness of carbon-based nanocomposite materials $[15,17,19,23]$. Pei et al. [77] showed that with increased substrate bias the films transform from columnar to glassy with a subsequent increase in hardness. Similar behavior with respect to the microstructure is seen in the present study (cf. Figure 5) although the same bias voltage is applied for both deposition methods, since the ion bombardment in the HiPIMS case favors dense film growth. To shed a light on the influence of the above mentioned parameters on the film hardness in the present study, nanoindentation measurements were performed on films grown by DCMS (0.6 kW average power) and HiPIMS exhibiting similar C/Ti ratios, and for films with similar amounts of free C. For films with C/Ti ratios of $\sim 0.36$ (morphology shown in Figures 5 (a) and (b), hardness values of $10 \pm 0.4$ and $21 \pm 1.0 \mathrm{GPa}$ were obtained for DCMS and HiPIMS, respectively. The films with C/Ti ratios slightly above 1, see Figures 5 
(e) and (d), showed values of $6 \pm 0.3$ and $27 \pm 1.6 \mathrm{GPa}$. Comparing films with equal amounts of free C, as shown in Figures 5 (a) and (d), hardness values of $10 \pm 0.4$ and $27 \pm 1.6 \mathrm{GPa}$, respectively, are obtained. No explanations on the observed differences in hardness can thus be found in stoichiometry or amounts of free C. Thus, the influence of morphology on hardness in the present study is consistent with previous reports [77], and furthermore indicates that in the present case, the $\mathrm{C} / \mathrm{Ti}$ ratio and amounts of free $\mathrm{C}$ are subordinate to morphology with regards to influencing hardness.

The effect of the C/Ti ratio and free $\mathrm{C}$ on the resistivity of DCMS and HiPIMS grown films is presented in Figure 6 (a) and (b), respectively. The pure Ti films exhibit similar resistivity for both deposition methods. Upon $\mathrm{C}$ incorporation and increase of the C/Ti ratio to $\sim 2.5$, the resistivity of the HiPIMS grown films increases from $\sim 200$ to $\sim 800 \mu \Omega \mathrm{cm}$, while the resistivity values of the DCMS films grown using an average power of $0.6 \mathrm{~kW}$ increase more than two orders of magnitude for the same C/Ti ratio range. By increasing the DCMS average power to $2 \mathrm{~kW}$, resistivity values similar to those acquired for HiPIMS is attained for the same C/Ti ratio (Figure 6 (a). The difference in resistivity between the 0.6 and $2 \mathrm{~kW}$ average target power DCMS film can possibly be understood when considering the difference in $\mathrm{O}$ contamination (cf. Figure 3) between the two groups. Furthermore, it has been reported that the conductivity in TiC/a-C:H nanocomposites is suppressed when the amount of the a-C:H matrix separating the TiC grains is increased $[15,78]$. Moreover, as shown for the WC/a-C system by Sanjinés et al [79], decreased grain sizes will result in increased resistivity due to grain boundary scattering. Here, this relation cannot be confirmed, considering the opposite trends in grain sizes for the two deposition methods as functions of $\mathrm{C}$ content as indicated in Figure 4. However, the fact that the amount of matrix, the decrease in grain sizes, as well as oxygen content is more pronounced for the films grown by DCMS at $0.6 \mathrm{~kW}$ is consistent with the trends observed in Figure 6 (a). When plotting the film resistivity as a function of 
free C (Figure 6 (b), DCMS films deposited at $2 \mathrm{~kW}$ show resistivity values matching those of films grown by HiPIMS. This underlines the significance of a-C matrix amount (i.e. grain separation, or quenched crystal growth resulting in decreased grain sizes) for the film resistivity for the films in the present study. The DCMS films deposited with an average power of $2 \mathrm{~kW}$ are thus in better agreement with earlier reports of resistivity for the TiC/a-C system $[10,20,65]$ than the DCMS films grown using an average power of $0.6 \mathrm{~kW}$. The resistivity values of the $0.6 \mathrm{~kW}$ DCMS series are thus an effect of the lower power applied to the target, and the high resistivity values can be avoided by increasing the deposition rate, i.e. decreasing the levels of contamination.

\section{Conclusions and Summary}

Ti-C films were reactively deposited employing high power impulse magnetron sputtering (HiPIMS) and direct current magnetron sputtering (DCMS). Analysis of the structural, bonding and compositional characteristics revealed that the deposited films are nanocomposite $\mathrm{Ti} / \mathrm{TiC}$, TiC, or TiC/a-C:H depending on the $\mathrm{C}_{2} \mathrm{H}_{2}$ flow and deposition method, where HiPIMS for $\mathrm{C}_{2} \mathrm{H}_{2}$ flows from 4 to $10 \mathrm{sccm}$ resulted in $\mathrm{TiC}_{\mathrm{x}}$ films and $\mathrm{TiC} / \mathrm{a}-\mathrm{C}$ for higher flows. For DCMS, $\mathrm{C}_{2} \mathrm{H}_{2}$ flows above $4 \mathrm{sccm}$ produced TiC/a-C:H coatings.

When employing HiPIMS, the process shows a wide and stable transition zone between metallic and compound target modes, ranging from $\sim 6 \mathrm{sccm}$ to at least $15 \mathrm{sccm}$. Within this flow interval, the stoichiometry of the resulting films was found to stabilize at a C/Ti ratio of $\sim 1$. The formation of free carbon for the HiPIMS grown films prior to the $\mathrm{C} / \mathrm{Ti}$ ratio of 1 was found to be low, resulting in near stoichiometric $\mathrm{TiC}_{\mathrm{x}}$ films, whereas the DCMS films were more disposed to form free $\mathrm{C}$, with resulting $\mathrm{TiC}_{\mathrm{x}} / \mathrm{a}-\mathrm{C}$ films with lower stoichiometry in the carbide phase. The carbide formation closer to stoichiometry for the HiPIMS films was attributed to the high plasma density inherent in the HiPIMS process. Comparison of films 
grown using HiPIMS and DCMS at equal deposition rates showed that the HiPIMS grown films exhibit higher hardness as well as lower resistivity values. Overall, the DCMS process and film properties of thereof were found to agree with previous reports of the $\mathrm{TiC} / \mathrm{a}-\mathrm{C}(: \mathrm{H})$ material system, and deviations from the literature were found to be a consequence of the comparably lower average power and deposition rate applied to the cathode during the DCMS experiments (as confirmed by depositions using higher average power), thus leading to a porous microstructure.

\section{Acknowledgements}

The authors should like to acknowledge Dr. Jens Jensen for ToF-ERDA measurements and Mr. Daniel Magnfält for providing the $\mathrm{H}$ reference sample. Tandem laboratory (Uppsala University) is acknowledged for ToF-ERDA facilities. Dr Axel Flink, Dr. Andrej Furlan, and Mr. Jonas Lauridsen are acknowledged for assisting with hardness, XPS, and resistivity measurements, respectively. Dr. Tomáš Kubart, Prof. Joseph E. Greene, Prof. Ivan Petrov, and Dr. Henrik Pedersen are acknowledged for useful discussions. The authors (MS, UH and KS) should like to acknowledge financial support from the Swedish Research Council (VR) through the contracts 621-2005-3245, 621-2008-3222, and 623-2009-7348, respectively. 


\section{References}

[1] L.E. Toth, Transition metal carbides and nitrides, Academic Press, New York (1971)

[2] W. Schintlmeister,O. Pacher, K. Pfaffinger., J. Electrochem. Soc. 123 (1976) 924.

[3] H. Randhawa, Thin Solid Films 153 (1987) 209.

[4] X.-Zhao Ding, Y.J. Li, Z. Sun, B.K. Tay, S.P. Lau, G.Y. Chen, W.Y. Cheung, S.P. Wong, J. Appl. Phys. 88 (2000) 6842.

[5] M-P. Delplancke-Ogletree, Othron, O.R., J. Vac. Sci. Technol., A 15 (1997) 1943.

[6] A. K. Dua, V. C. George and R. P. Agarwala, R. Krishnan, Thin Solid Films, 121 (1984) 35

[7] Y. Pei, D. Galvan, J. De Hosson, A. Cavaleiro, Surf. Coat. Technol. 198 (2005) 44.

[8] M. Stüber, Surf. Coat. Technol. 150 (2002) 218.

[9] B. Feng, D.M. Cao, W.J. Meng, J. Xu, R.C. Tittsworth, L.E. Rehn, P.M. Baldo, G.L. Doll, Surf. Coat. Technol. 148 (2001) 153.

[10] S. Inoue, Wada, K. Koterazawa, Vacuum 59 (2000) 735.

[11] E. Kusano, A. Sato, N. Kikuchi, H. Nanto, A. Kinbara, Surf. Coat. Technol. 120-121 (1999) 378.

[12] J.E. Sundgren, B.O. Johansson, S.E. Karlsson, Thin Solid Films 80 (1981) 77.

[13] I. Ritchie, Thin Solid Films 72 (1980) 65.

[14] H.O. Pierson, Handbook of refractory carbides and nitrides, Noyes Publication, New Jersey (1996)

[15] W. Gulbinski, S. Mathur, H. Shen, T. Suszko, A. Gilewicz, B. Warcholiski, Appl. Surf. Sci. 239 (2005) 302.

[16] D. McKenzie, L. Briggs, Sol. Energ. Mater. 6 (1981) 97.

[17] P. Mayrhofer, C. Mitterer, L. Hultman, H. Clemens, Prog. Mater Sci. 51 (2006) 1032.

[18] T. Zehnder, P. Schwaller, F. Munnik, S. Mikhailov, J. Patscheider, J. Appl. Phys. 95 (2004) 4327.

[19] T. Zehnder, J. Patscheider, Surf. Coat. Technol. 133 (2000) 138.

[20] E. Lewin, O. Wilhelmsson, U. Jansson, J. Appl. Phys. 100 (2006) 054303. 
[21] A. Voevodin, J. Zabinski, J. Mater. Sci. 33 (1998) 319-327.

[22] J. Sanchez-Lopez, D. Martinez-Martinez, C. Lopez-Cartes, A. Fernandez, Surf. Coat. Technol. 202 (2008) 4011.

[23] D. Martinez-Martinez, C. Lopez-Cartes, A. Fernandez, J. Sanchez-Lopez, Thin Solid Films 517 (2009) 1662.

[24] I. Petrov, P.B. Barna, L. Hultman, J.E. Greene, J. Vac. Sci. Technol., A 21 (2003) S117.

[25] V. Kouznetsov, K. Macák, J. M. Schneider, U. Helmersson, I. Petrov, Surf. Coat. Technol. 122 (1999) 290.

[26] U. Helmersson, M. Lattemann, J. Bohlmark, A. Ehiasarian, J. Gudmundsson, Thin Solid Films 513 (2006) 1.

[27] K. Sarakinos, J. Alami, S. Konstantinidis, Surf. Coat. Technol. 204 (2010) 1661.

[28] J. Alami, J.T. Gudmundsson, J. Bohlmark, J. Birch, U. Helmersson, Plasma Sources Sci. Technol. 14 (2005) 525.

[29] K. Macák, V. Kouznetsov, J. Schneider, U. Helmersson, I. Petrov, J. Vac. Sci. Technol., A $18(2000) 1533$.

[30] J.W. Bradley, S. Thompson, Y.A. Gonzalvo, IEEE Conference Record - Abstracts. PPPS-2001 Pulsed Power Plasma Science 2001. $28^{\text {th }}$ IEEE International Conference on Plasma Science and $13^{\text {th }}$ IEEE International Pulsed Power Conference (Cat. No.01CH37255) 10 (2001) 376.

[31] A.P. Ehiasarian, R. New, W.-D. Münz, L. Hultman, U. Helmersson, V. Kouznetsov, Vacuum 65 (2002) 147.

[32] J. Bohlmark, M. Lattemann, J. Gudmundsson, A. Ehiasarian, Y. Arandagonzalvo, N. Brenning, U. Helmersson, Thin Solid Films 515 (2006) 1522.

[33] J. Alami, P.O.Å. Persson, D. Music, J.T. Gudmundsson, J. Bohlmark, U. Helmersson, J. Vac. Sci. Technol., A 23 (2005) 278.

[34] V. Sittinger, F. Ruske, W. Werner, C. Jacobs, B. Szyszka, D. Christie, Thin Solid Films 516 (2008) 5847.

[35] A. Ehiasarian, P.Eh. Hovsepian ,L. Hultman ,U. Helmersson Thin Solid Films 457 (2004) 270.

[36] M. Lattemann, U. Helmersson, J.E. Greene, Thin Solid Films 518 (2010) 5978.

[37] J. Alami, P. Eklund, J. Andersson, M. Lattemann, E. Wallin, J. Bohlmark, P. Persson, U. Helmersson, Thin Solid Films 515 (2007) 3434. 
[38] J. Alami, K. Sarakinos, F. Uslu, C. Klever, J. Dukwen, M. Wuttig, J. Phys. D: Appl. Phys. 42 (2009) 115204.

[39] S. Konstantinidis, J. Dauchot, M. Hecq, Thin Solid Films 515 (2006) 1182.

[40] J. Paulitsch, P. Mayrhofer, C. Mitterer, W. Munz, in: Society of Vacuum Coaters $50^{\text {th }}$ Annual Technical Conference Proceedings, 2007, p. 150.

[41] J. Alami, K. Sarakinos, F. Uslu, M. Wuttig, J. Phys. D: Appl. Phys. 42 (2009) 015304.

[42] E. Wallin, U. Helmersson, Thin Solid Films 516 (2008) 6398.

[43] K. Sarakinos, J. Alami, C. Klever, M. Wuttig, Surf. Coat. Technol. 202 (2008) 5033.

[44] M. Aiempanakit, U. Helmersson, A. Aijaz, P. Larsson, R. Magnusson, J. Jensen, T. Kubart, Surf. Coat. Technol. 205 (2011) 4828-4831.

[45] J. Benedikt, R.V. Woen, S.L.M. van Mensfoort, V. Perina, J. Hong, M.C.M. van de Sanden, Diamond Relat. Mater. 12 (2003) 90.

[46] D. Galvan, Y.T. Pei, J.Th.M. De Hosson, J. Vac. Sci. Technol., A 24 (2006) 1441

[47] A. Czyzniewski, W. Precht, J. Mater. Process. Technol. 157-158 (2004) 274.

[48] H. Ljuncrantz, T. Rosell, U.S. Patent No. US 2007/0084401 A1 (2007).

[49] J. R. Tesmer, M. Nastasi, Handbook of modern ion beam materials analysis, Materials Research Society, Pittsburgh, 1995

[50] E. Lewin, M. Gorgoi, F. Schäfers, S. Svensson, U. Jansson, Surf. Coat. Technol. 204 (2009) 455.

[51] M. Jansson, CONTES instructions manual, 2004

[52] W.C. Oliver, G.M. Pharr, J. Mater. Res. 7 (1992) 1564.

[53] S. Berg, T. Nyberg, Thin Solid Films 476 (2005) 215.

[54] T. Kubart, M. Aiempanakit, J. Andersson, T. Nyberg, S. Berg, U. Helmersson, Surf. Coat. Technol. 205 (2011) S303-S306.

[55] D. Depla, R.D. Gryse, J. Vac. Sci. Technol., A 20 (2002) 521.

[56] H.F. Winters, J.W. Coburn, Surf. Sci. Rep. 14 (1992) 161.

[57] M.N.R. Ashfold, P.W. May, C.A. Rego, N.M. Everitt, Chem. Soc. Rev., 23 (1994) 21

[58] W. Jacob, C. Hopf, M. Schlüter, Phys. Scr. T124 (2006) 32.

[59] C. Hopf, a von Keudell, W. Jacob, J. Appl. Phys. 94 (2003) 2373. 
[60] J. Benedikt, D.C. Schram, M.C.M. van de Sanden, J. Phys. Chem. A 109 (2005) 10153.

[61] J. Benedikt, J. Phys. D: Appl. Phys. 43 (2010) 043001.

[62] S. Berg, I.V. Katardjiev, J. Vac. Sci. Technol. A 17 (1999) 1916.

[63] H.J. Kang, Y.S. Kim, Surf. Sci. 226 (1990) 93.

[64] E. Lewin, P. Persson, M. Lattemann, M. Stüber, M. Gorgoi, A. Sandell, C. Ziebert, F. Schäfers, W. Braun, J. Halbritter, Surf. Coat. Technol. 202 (2008) 3563.

[65] E. Lewin, E. Olsson, B. André, T. Joelsson, Å. Öberg, U. Wiklund, H. Ljungcrantz, U. Jansson, Plasma Processes Polym. 6 (2009) S928.

[66] M. Magnuson, E. Lewin, L. Hultman, U. Jansson, Phys. Rev. B: Condens. Matter 80 (2009) 1.

[67] J. Musil, S. Kadlec, J. Vyskocil, V. Poulek, Surf. Coat. Technol. 39-40 (1989) 301.

[68] P. Kelly, R. Arnell, Vacuum 56 (2000) 159.

[69] S. Zhang, X. Bui, J. Jiang, X. Li, Surf. Coat. Technol. 198 (2005) 206.

[70] J.M. Anton, B. Mishra, J.J. Moore, Surf. Eng. 23 (2007) 23.

[71] S. Inoue, Y. Wada, K. Koterazawa, Vacuum 59 (2000) 735.

[72] V.J. Benavides, C.D. Salazar, M.E. Espitia, D.M. Devia, A. Devia, Phys. Scr. T131 (2008) 014021.

[73] E.F. Chinaglia, I.C. Oppenheim, in: Mater. Res. Soc. Symp. Proc., Warrendale, Pa., Materials Research Society; 1999, 2001, p. 3.

[74] A.A. Voevodin, M. A. Capano, S.J.P. Laube, M.S. Donley, J.S. Zabinski, Thin Solid Films 298 (1997) 107.

[75] L. Nobili, F. Pagano, P.L. Cavallotti, Int. J. Surf. Sci. Eng. 2 (2008) 350.

[76] Y.T. Pei, D. Galvan, J.Th.M. De Hosson, Acta Mater. 53 (2005) 4505.

[77] Y.T. Pei, D. Galvan, J.Th.M. De Hosson, C. Strondl, J. Eur. Ceram. Soc. 26 (2006) 565.

[78] A. Fernandes, L. Cunha, C. Moura, F. Vaz, P. Carvalho, E. Lebourhis, P. Goudeau, J.

Riviere, N. Parreira, Surf. Coat. Technol. 202 (2007) 946.

[79] R. Sanjinés, M.D. Abad, C. Vâju, R. Smajda, M. Mionić, A. Magrez, Surf. Coat. Technol. (2011) 1. 


\section{Figure captions}

Figure 1. (a) C/Ti ratio of films grown using DCMS ( $\square$ ) and HiPIMS $(\diamond)$ conditions, as determined by XPS. And (b), the deposition rate for the respective process. Lines are guide for the eye.

Figure 2. High resolution XPS spectra of the C1s region for films of various compositions deposited by (a) DCMS and (b) HiPIMS. Intensities have been normalized to the most intense peak in each spectrum. Some of the shown spectra have been shifted to compensate for charge referencing problems, see section 2 for details.

Figure 3. (a) The relative peak area of C-C bonds (as obtained from curve fitting of XPS data), and (b) oxygen content versus C/Ti ratio for DCMS $0.6 \mathrm{~kW}$ (squares), DCMS $2 \mathrm{~kW}$ (circles), and HiPIMS (diamonds). The lines are guides for the eye.

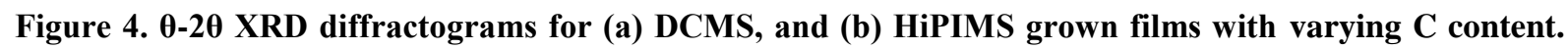
Reference positions for $\mathrm{Ti}(\nabla)$ and $\mathrm{TiC}(\bigcirc)$ phases are shown. The substrate reflections are marked with "s".

Figure 5. SEM cross section micrographs of DCMS (a), (c), and (e) and HiPIMS (b) and (d) films, with a similar C/Ti ratio of $\sim 0.36$ (a), (b), and (c) and slightly above 1 (d) and (e). The scale bar is valid for all four micrographs.

Figure 6. Electrical resistivity as measured as measured by four-point probe plotted as a function of (a) $\mathrm{C} / \mathrm{Ti}$ ratio, and (b) free $\mathrm{C}$. Lines are guide for the eye. 


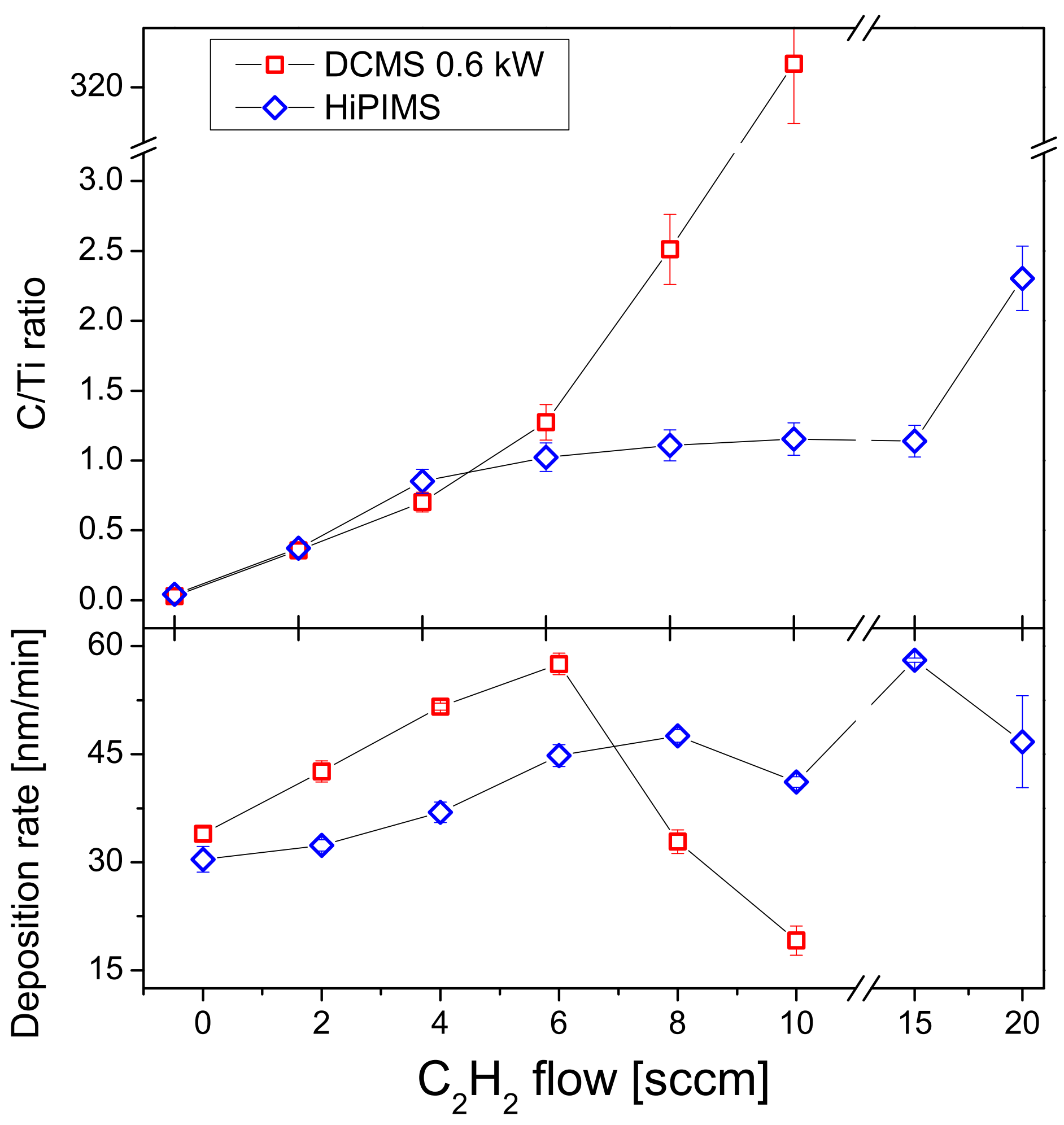



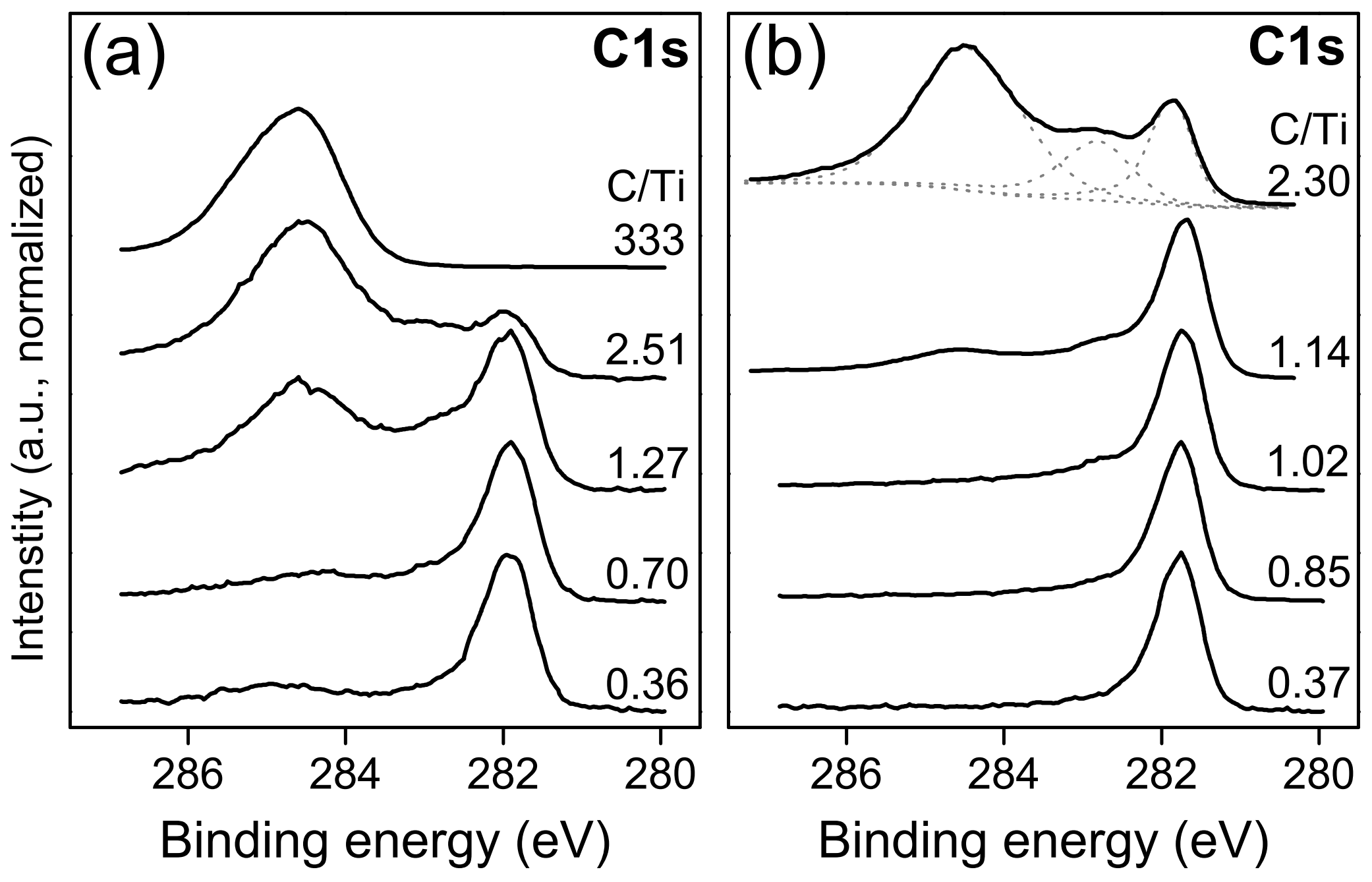


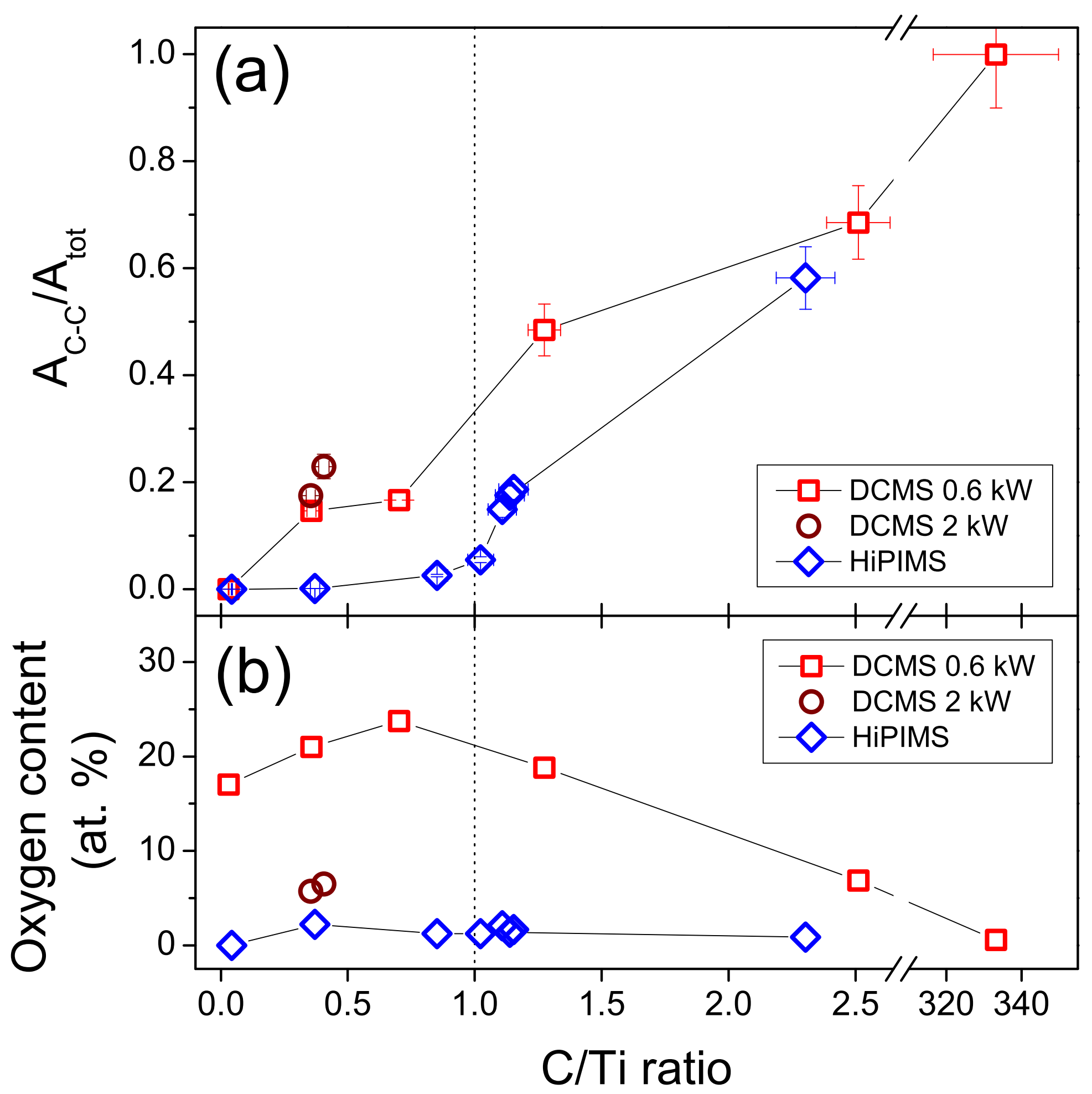


(a) DCMS (0.6 kW) C/Ti=0.36
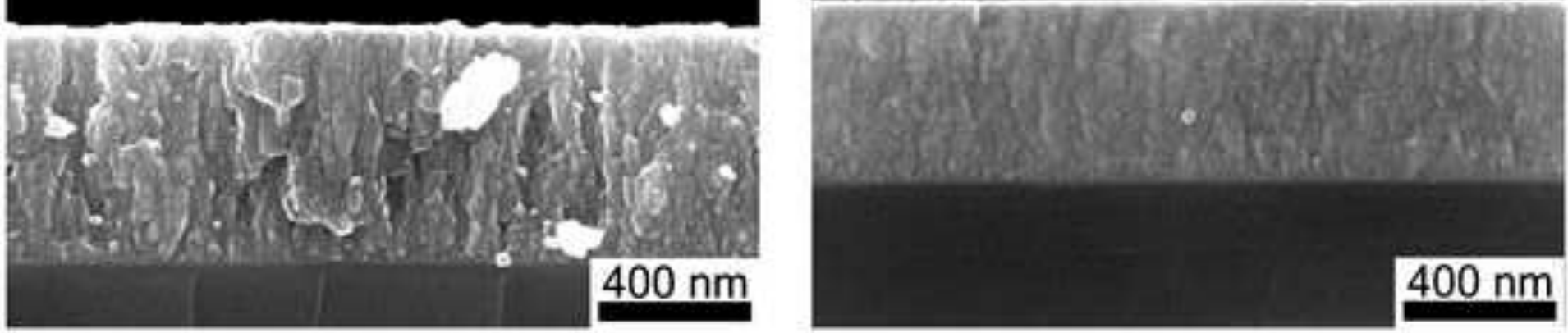

(C) DCMS (2 kW) C/Ti=0.41
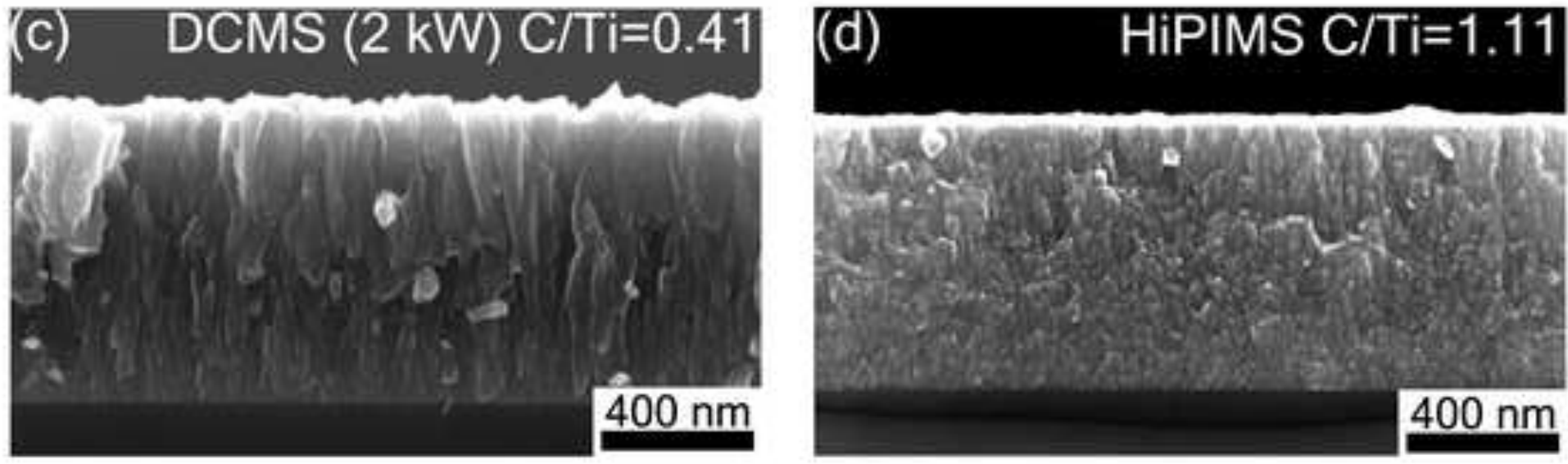

\section{(e) DCMS $(0.6 \mathrm{~kW}) \mathrm{C} / \mathrm{Ti}=1.27$}

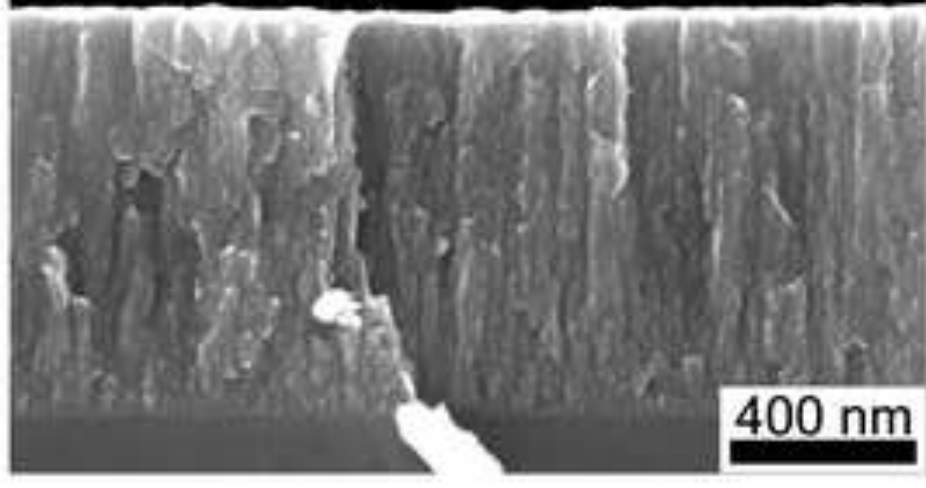


